\title{
Cardiovascular risk in Idiopathic Pulmonary Fibrosis
}

\author{
Emma Denneny ${ }^{1}$ and Muhunthan Thillaii ${ }^{2,3 *}$ \\ ${ }^{1}$ University College London, UK \\ ${ }^{2}$ Royal Papworth Hospital, UK \\ ${ }^{3}$ Department of Medicine, University of Cambridge, UK
}

Submission: September18, 2018; Published: September 21, 2018

*Corresponding author: MuhunthanThillai, Papworth Hospital NHS Foundation Trust, Papworth Everard, Cambridge CB23 3RE, UK, Email: muhunthan.thillai@nhs.net

\section{Opinion}

Idiopathic Pulmonary Fibrosis (IPF) is a progressive interstitial lung disease with a median survival of 3-5 years following diagnosis [1]. Patients most commonly present with cough or dyspnea, and the disease is characterized by a chronic, progressive parenchymal fibrosis with a Usual Interstitial Pneumonia (UIP) histological pattern. On CT scanning this is defined as basal predominant reticulation, traction bronchiectasis, and in some cases, honeycombing. At time of biopsy, UIP is histologically defined as paraseptal fibrosis with architectural distortion and fibroblastic foci. The natural course of the disease is one which leads to progressive respiratory failure and death [1]. Until recently, treatment consisted of regular surveillance, symptom relief, pulmonary rehabilitation, managing of comorbidities (e.g. gastro-oesophageal reflux) and ultimately palliative care or referral for lung transplantation [2]. Following the 2014 publications of the ASCEND [3] and IMPULSIS [4] trials, two new antifibrotic treatments (Pirfenidone and Nintedanib) have become widely available for IPF patients who meet certain criteria. These criteria are determined differently by different healthcare bodies around the world e.g. in the United Kingdom patients must have had a multi-disciplinary team diagnosis of IPF and a forced vital capacity (FVC) between 50 and $80 \%$ to be eligible for treatment with an antifibrotic medication. Both of these medications have been shown to slow the progression of the disease and therefore delay functional decline $[3,4]$.

However, the mortality and morbidity burden in IPF is not only related to the disease process itself, but also due to a number of co-morbid conditions, which can be partly explained by the disease being more prevalent in the elderly, with median age of onset at 66 years $[2,5,6]$. Co-morbidities can be either pulmonary or extra-pulmonary. Pulmonary conditions include pulmonary hypertension (3-86\%), obstructive sleep apnea (5.9$91 \%)$, lung cancer (3-23\%), and chronic obstructive pulmonary disease (COPD) (6-67\%) [6]. Extra-pulmonary conditions include gastro-oesophageal reflux (0-94\%) diabetes mellitus (10-42\%) as well as depression and anxiety (21-49\%) [6].

One important co-morbidity is Cardiovascular Disease (CVD) which is a serious but potentially modifiable association that affects patients with IPF [7]. CVD manifestations include pulmonary hypertension, heart failure, Coronary Artery Disease (CAD) cardiac arrhythmias and stroke [8].Atherosclerosis and pulmonary fibrosis have some similar pathophysiological changes, with both developing from excessive inflammation and fibrosis, driven by elevated cytokine and chemokine expression [9]. In pulmonary hypertension, chronic hypoxia causes cardiac ischemia and the combination of chronic inflammation and elevated pulmonary pressures also increase the risk for developing cardiac arrhythmias [8]

Population studies have identified a specific increased risk of CVD in patients with IPF.Primary health care data from the Health Improvement Network in the United Kingdom showed an increased risk of Acute Coronary Syndrome (ACS) (OR 1.53; 95\% CI 1.15-2.03), angina (OR 1.84; 95\% CI 1.48-2.29) and DVT (OR 1.98; 95\% CI, 1.13-3.48) prior to the diagnosis of IPF. This is independent of confounding factors such as smoking, age or gender [10]. Post diagnosis population studies reveal an increased risk of ACS (RR 3.14; 95\% CI 2.02-4.87) and DVT (RR 3.39; 95\% CI 1.57-7.28) [10]. A subsequent multivariate analysis in IPF using data taken from the Korean Heart Study showed that IPF was an independent risk factor for CAD following adjustments for age, hypertension, diabetes and hypercholesterolemia [11]. Data from patients with IPF undergoing lung transplant assessment (where part of the work up included coronary angiography) revealed that $68 \%$ of patients had CAD [12]. This is supported by a cross-sectional study of 630 patients also referred for lung transplant. Here, they demonstrated an increased prevalence of CAD in patients with fibrotic lung disease compared to nonfibrotic lung disease (OR 2.18; 95\% CI 1.17-4.06) [9]. Further analysis of lung transplant data reveals that the incidence of CAD 
seems higher than in other chronic lung diseases such as COPD [13]. Importantly, IPF patients with significant CAD had worse outcomes than those with none or non-significant disease [13]. One interesting additional argument for the increasing burden of CVD is the concept that with the management of a complex disease such as IPF, there may be less awareness and emphasis on standard medical complaints (such as CVD) resulting in a reduced use of statins and antihypertensive medication [10].

Early recognition and treatment of CVD in this already high-risk population is important.Current methods include coronary angiography, detection of coronary calcifications on HRCT, systemic blood pressure measurement, monitoring serum cholesterol and use of validated risk calculators such as the Framingham and the QRISK-2 scores [1]. The QRISK-2 scoring system uses a number of parameters to calculate both the percentage risk of having a heart attack or stroke within the next 10 years, as well as a relative risk compared to an adult of the same age, sex, and ethnicity in the general population [14]. Preliminary data where this tool has been applied in IPF identified a cohort of patients where two thirds were deemed to be at 'high' cardiovascular risk[15]. This suggests a role for improved screening at diagnosis to allow for appropriate cardiovascular intervention. Once screening has picked up patients at high cardiovascular risk, the responsibility for managing this needs to be clearly delineated to either the pulmonary physician treating the IPF or to the patient's general practitioner. Given the high burden of disease and the significantly worse outcomes of patients with IPF and CVD compared to IPF alone, further studies are needed to validate this finding and identify other ways in which cardiovascular risk can be reduced in patients with IPF.

\section{Conflicts of Interest}

ED reports no conflicts of interest. MT has received travel support and consultancy fees from Roche and Boehringer Ingelheim.

\section{References}

1. Oldham JM, Collard HR (2017) Comorbid Conditions in Idiopathic Pulmonary Fibrosis: Recognition and Management. Frontiers in Medicine 4: 123.

2. Raghu G, Richeldi L (2017) Current approaches to the management of idiopathic pulmonary fibrosis. Respiratory Medicine 129: 24-30.
3. King TE, Bradford WZ, Castro Bernadini S, Fagan EA, Glaspole I, et al. (2014) A Phase 3 Trial of Pirfenidone in Patients with Idiopathic Pulmonary Fibrosis. The New England Journal of Medicine 370(22): 2083-2092.

4. Richeldi L, Du Bois RM, Raghu G, Azuma A, Brown KK, et al. (2014) Efficacy and safety of ninte danib in idiopathic pulmonary fibrosis. The New England Journal of Medicine 370(22): 2071-2082.

5. Vancheri C, Cottin V, Kreuter M, Hilberg O (2015) IPF, comorbidities and management implications. Sarcoidosis Vasculitis and Diffuse Lung Diseases 32 (Suppl 1): 17-23.

6. Raghu G, Amatto VC, Behr J, Stowasser S (2015) Comorbidities in idiopathic pulmonary fibrosis patients: a systematic literature review. European Respiratory Journal 46(4): 1113-1130.

7. Dalleywater W, Powell HA, Hubbard RB, Navaratnam V (2015) Risk factors for cardiovascular disease in people with idiopathic pulmonary fibrosis: a population-based study. Chest 147(1): 150-156.

8. Agrawal A, Verma I, Shah V, Agarwal A, Sikachi RR (2016) Cardiac manifestations of idiopathic pulmonary fibrosis. Intractable and Rare Diseases Research 5(2): 70-75.

9. Kizer JR, Zisman DA, Blumenthal NP, Kotloff RM, Kimmel SE, et al. (2004) Association Between Pulmonary Fibrosis and Coronary Artery Disease. Archives of Internal Medicine 164(5): 551-556.

10. Hubbard RB, Smith C, Le Jeune I, Gribbin J, Fogarty AW (2008) The association between idiopathic pulmonary fibrosis and vascular disease: a population-based study. American Journal of Respiratory and Critical Care Medicine 178(12): 1257-1261.

11. Kim WY, Mok Y, Kim GW, Baek SJ, Yun YD, et al. (2015) Association between idiopathic pulmonary fibrosis and coronary artery disease: a case-control study and cohort analysis. Sarcoidosis, Vasculitis and Diffuse Lung Diseases: Official journal of WASOG 31(4): 289-296.

12. Collard HR, Ward AJ, Lanes S, Cortney Hayflinger D, Rosenberg DM (2012) Burden of illness in idiopathic pulmonary fibrosis. Journal of Medical Economics 15(5): 829-835.

13. Nathan SD, Basavaraj A, Reichner C, Shlobin OA, Ahmad S, et al (2010) Prevalence and impact of coronary artery disease in idiopathic pulmonary fibrosis. Respiratory Medicine 104(7): 1035-1041.

14. Collins GS, Altman DG (2012) Predicting the 10 year risk of cardiovascular disease in the United Kingdom: independent and external validation of an updated version of QRISK2. British Medical Journal 344: e4181.

15. Denneny E, Tailor B, Aggarwal A, Millward K, Fiddler C, et al (2018) Application of the QRISK-2 Score Identifies an Increased Cardiovascular Risk in Patients with Idiopathic Pulmonary Fibrosis at Time of Diagnosis. American Journal of Respiratory and Critical Care Medicine 197: A7471. 
(CC) This work is licensed under Creative

BY DOI: 10.19080IJOPRS.2018.03.555623
Your next submission with Juniper Publishers will reach you the below assets

- Quality Editorial service

- Swift Peer Review

- Reprints availability

- E-prints Service

- Manuscript Podcast for convenient understanding

- Global attainment for your research

- Manuscript accessibility in different formats ( Pdf, E-pub, Full Text, Audio)

- Unceasing customer service

Track the below URL for one-step submission https://juniperpublishers.com/online-submission.php 